\title{
As Variedades de Empréstimos
}

\author{
(Varieties of Loan Translations)
}

Francis Henrik AUBERT

(USP)

\begin{abstract}
In translating culturally marked terms, a frequent procedure is the loan, which leaves the apprehension of meaning to the co-text or other sources. At a first glance, the loan would seem to be the simplest procedure, standing as a sort of zero degree of interference of the translational operation. A detailed examination of a corpus of translations from Brazilian Portuguese into American English suggests, however, that the loan procedure may be indeed fairly complex, involving a spectrum of translation decisions far removed from any zero degree of the translational act.
\end{abstract}

KEY-WORDs: Translation; Loan; Contrastive linguistics.

RESUMO: Na tradução de termos culturalmente marcados, um procedimento freqüente é o empréstimo, que remete ao co-texto ou a outros recursos a depreensão do sentido. Aparentemente, o empréstimo constituiria o procedimento mais simples, representando uma espécie de nivel zero de interferência da operação tradutória. Um exame detalhado de um corpus de traduções do português brasileiro para o inglês americano sugere, no entanto, que o uso do empréstimo pode ser bastante complexo, envolvendo um conjunto de decisões tradutórias bastante distantes do nível zero do ato tradutório.

PalavRas-CHAVE: Tradução; Empréstimo; Lingüística contrastiva.

\section{Introdução}

O empréstimo de termos e expressões entre as línguas e as culturas é um procedimento provavelmente tão antigo quanto o contato entre povos de idiomas ou falares distintos. O empréstimo deixa traços nos substratos e, principalmente, nos superestratos descritos pela ciência filológica. $\mathrm{O}$ empréstimo, em suas diversas matizes, enriquece as línguas ou as desfigu-

D.E.L.T.A., 19:EsPECIAL, 2003 (27-42) 
ra, a depender do ponto de vista cultural assumido e da correlação - momentânea ou duradoura - das forças de dominação e de resistência em confronto e a depender, ainda, do recorte sincrônico assumido. O destino dos empréstimos, em qualquer momento dado, é sempre incerto: ou desaparecem, substituídos por soluções vernaculares; ou passam por transformações, quer de significante, quer de significado, e, deste modo, deixam de lado seu caráter de empréstimo para tornarem-se parte integrante do universo cultural que os acolheu. Já vernaculizados, podem vir a tornar-se novos empréstimos, agora em terceiras línguas. ${ }^{1}$

Como locus privilegiado de contato lingüístico cultural, a tradução ou, mais precisamente, os textos traduzidos - podem conter e, a mais das vezes, de fato contêm, explícitas ou veladas, formas lexicais, sintáticas e mesmo conceptuais originariamente emprestadas de outra língua e/ou de outra cultura. É pela tradução que o estrangeirismo, de qualquer tipo, via de regra faz a sua primeira incursão. A questão do empréstimo assume, pois, aspectos lingüísticos, sociolingüísticos, culturais, sincrônicos e diacrônicos, oferecendo, pois, um amplo campo de pesquisa e de reflexão. Dentro desta perspectiva geral, o presente estudo tem por objetivo esmiuçar, no âmbito da tradução, as formas lexicais assumidas pelo empréstimo e o seu peso no quadro geral dos diversos procedimentos disponíveis à operação tradutória.

\section{A conceituação do empréstimo}

Vinay e Darbelnet (1958) concebem o empréstimo como sendo "a própria negação da tradução”. Em tese, o termo, expressão ou frase do original aparece intacto, não traduzido, no texto em língua-meta (LM). Procedimento freqüentemente condenável, pode, no entanto, sempre na visão de Vinay, apresentar "a vantagem de enriquecer a LM com uma utilidade lexical concreta de fácil manejo.”

1 Este último caso é ilustrado na linguagem atual da informática, em que deletar, tido e havido como anglicismo, remonta, na realidade, ao verbo latino delere. Da mesma origem latina é o termo vernacular delir. 
Wills (1982:100), comentando a proposta de Vinay e Darbelnet, questiona a inclusão do empréstimo em um sistema classificatório de procedimentos de tradução:

"(...) The inclusion of emprunt in the classification system would seem out of place, since a direct borrowing which has been lexically adapted to a Target Language, at least in terms of spelling and pronunciation, cannot be called a translation procedure in the narrower sense of the word, even if more liberal standards are applied."

Nesta visão, portanto, o empréstimo seria tão marginal ao processo tradutório a ponto de poder ser ignorado enquanto procedimento (ainda que não como fenômeno lingüístico tout court).

Newmark (1981) denomina o fenômeno como transferência, abarcando, sob o conceito, também as expansões explicativas (notas, glossários e explicações diluídas no texto) que freqüentemente acompanham o termo transferido ou emprestado.

Adotando de Newmark o designativo transferência, entendida como a introdução de material textual da Língua Fonte (LF) no texto em LM, Barbosa (1990) subcategoriza a transferência nas diversas formas que pode assumir: 1) estrangeirismo (empréstimo senso estrito); 2) estrangeirismo transliterado (decalque grafo-fonológico); 3) estrangeirismo aclimatado (decalque lexical e/ou morfossintático); 4) estrangeirismo + uma explicação de seu significado (ou seja, o empréstimo acompanhado de explicitação). ${ }^{2}$

Para Vinay e Darbelnet, o empréstimo é o procedimento mais fácil para o tradutor. Barbosa (1990:100), com muita propriedade, discorda:

"Não acredito ... que o empréstimo seja um procedimento tão fácil assim. Ele é usado quando há uma divergência tão grande entre as línguas, entre as realidades extralingüísticas expressas por meio delas, que falta a uma itens lexicais possuídos pela outra para designar objetos ou exprimir conceitos desconhecidos pela primeira, o que representa grande dificuldade para o tradutor e obstáculo para a tradução (cf. Alves, 1983) e compreensão do TLT por seu leitor."

2 Comentários parentéticos deste autor. 
Observam-se, em síntese, duas principais linhas de pensamento acerca do empréstimo na tradução. Uma primeira sugere tratar-se de um procedimento menor, circunstancial, fácil, uma "mera cópia”, talvez sequer merecedor de figurar entre os procedimentos tradutórios no sentido estrito do termo. Representaria um fenômeno possível na tradução, em certas circunstâncias limitadas, mas de baixo interesse geral, exceto para o enriquecimento do vocabulário técnico das linguagens de especialidade (terminologia). No limite, dependendo do ponto-de-vista, poderia constituir elemento de risco cultural, sendo, por conseguinte, melhor evitados do que praticados.

Em oposição a essa linha, levanta-se uma segunda abordagem, entendendo o empréstimo como um verdadeiro procedimento de tradução, não como mera cópia, ${ }^{3}$ e que pode apresentar-se de formas variadas, inclusive em combinação com outros procedimentos. Esta hipótese interpretativa também contém um desdobramento para a política cultural. Assim, ainda que nem sempre destacada explicitamente, a abordagem proposta por Venuti (1995) redunda em valorizar o empréstimo, juntamente com os decalques sintáticos, lexicais e semânticos, como ferramenta tradutória que dá vida a uma opção deliberada de política cultural. Adotando uma linha de reflexão que remonta, no que tange à tradução, a Schleiermacher (1813), Venuti defende, na relação tradutória que se estabelece entre culturas periféricas e culturas centrais, uma opção deliberadamente "estrangeirizadora" (foreignizing), com vistas a evitar o apagamento da alteridade, tida como conveniente para a cultura central, dominante, mas, na essência, desvantajosa - posto que empobrecedora - para ambas as partes.

Estudos de natureza quantitativa sobre corpora de textos traduzidos confirmam a baixa freqüência do empréstimo como recurso tradutório. Em Alves (1983), um estudo baseado em corpus bilíngüe inglês $\rightarrow$ português de textos de ciências humanas, indicou uma ocorrência nula (0\%),

\footnotetext{
3 Sugeri alhures (Aubert, 1998) que o empréstimo não se confunde com a transcrição, esta sim, uma cópia real, sem interferência do tradutor, e que ocorre sempre que o original contiver um elemento lingüístico-conceptual ou cultural comum à LF e à LM (como, p. ex., uma fórmula química ou algébrica) ou específica de uma terceira língua (como, p. ex., um termo em alemão constante de um original francês traduzido para o português e mantido em sua forma germânica na tradução).
} 
tomando como unidade de contagem a palavra. Em Darin (1986), um trabalho similar sobre texto antropológico-literário, a ocorrência encontrada não excedeu 1\%. Em um outro estudo, tendo por variável a tipologia textual (Zanotto, 1983), para uma ocorrência geral de 2,54\% de empréstimos, constatou-se, nos textos corporativos, uma incidência um pouco maior, da ordem de 3,7\%, e de 2,7\% em textos literários. Em ambos os casos, frise-se, o peso maior dos empréstimos é representado pelos nomes próprios: topônimos, antropônimos e diversas razões sociais. Configurando-se, embora, como traço pertinente dos textos corporativos, a relevância quantitativa do empréstimo ainda é, em comparação com os demais procedimentos, bastante modesta. E nem poderia ser de outro modo, posto que uma incidência mais elevada certamente acarretaria dificuldades talvez intransponíveis de legibilidade do texto traduzido, e representaria, na prática, aí sim, uma efetiva renúncia ao traduzir.

O fato do empréstimo ser - e provavelmente dever ser - de baixa freqüência não significa, porém, que se trate de um fenômeno tradutório marginal ou secundário; nem, por ser, na aparência, mera "cópia" do original, menos crucial para o processo e para o produto tradutórios.

\section{A complexidade do empréstimo}

Mesmo à observação empírica, os empréstimos se mostram menos simples e transparentes do que se poderia supor.

No "front" puramente interno do português brasileiro, é notório o quanto já se procedeu a uma verdadeira antropofagia lexical em relação às línguas estrangeiras em geral (e ao inglês em particular), como ilustrado pelo uso de shopping em lugar de mall, office boy em lugar de messenger, "X", derivado de cheese, como sinônimo de lanche e não mais apenas como lanche com fatia de queijo (Aubert, 2001). Na linguagem de especialidade da informática, por muitos anos tida como exemplo claro de uma verdadeira invasão de anglicismos, o HD (hard disk) já enfrenta a competição de disco rígido (e o termo Winchester parece ter caído de vez em desuso). Nos

antropônimos e, em particular, nos topônimos, convivem, lado a lado, tradições distintas, resultando em múltiplas variantes: Pequim, Peking e 
Beijing; New York, Nova Iorque e o curioso - mas atualmente mais difundido híbrido - Nova York. O monarca britânico decapitado em 1649, é conhecido como Carlos I, mas o atual Príncipe de Gales é sempre identificado como Charles. Inversamente, campus e campi, embora ainda as formas mais usuais, vêm paulatinamente sendo substituídos por câmpus, invariável, seguindo o paradigma de lápis.

$\mathrm{Na}$ tradução, campo de confronto imediato entre as estruturas e os usos lingüísticos e culturais, a situação não há de ser menos complexa. A subcategorização proposta por Barbosa (vide acima) já aponta nessa direção. Para obter uma melhor compreensão do fenômeno em sua efetiva amplitude, porém, faz-se necessário empreender uma investigação baseada em corpus real. Com esse objetivo em vista, e considerando que os aspectos quantitativos poderiam vir a ter relevância pelo menos comparável aos qualitativos-taxionômicos, foram selecionadas duas obras representativas e, de forma direta ou indireta, descritivas da cultura brasileira: os dois primeiros capítulos ("A Terra" e "O Homem") de Os Sertões, de Euclides da Cunha, e a totalidade do romance Teresa Batista Cansada de Guerra, de Jorge Amado. Em cada um, foram assinalados todos os termos e expressões que, de algum modo, referem-se expressamente à realidade extra-lingüística brasileira (ecológica, da cultura material, social ou ideológica - vide Nida, 1945), incluindo-se, nesse levantamento, todas as recorrências dos mesmos termos e expressões, totalizando 962 ocorrências. A seguir, buscou-se localizar, nas respectivas traduções (vide Referências Bibliográficas), a equivalência tradutória oferecida para cada termo culturalmente marcado.

A priori, a natureza especial dos marcadores lingüísticos das especificidades culturais da LF sugere que são quatro as opções básicas de tradução: a omissão (evitando-se a dificuldade), o empréstimo (utilizando o co-texto como recurso suplementar), a explicitação explícita (recurso à paráfrase) ou implícita (diluição de alguns traços semânticos relevantes ao longo do texto), ou, ainda, a adaptação, este último procedimento redundando em um processo de aculturação. O quadro que se segue sintetiza os resultados encontrados para o corpus em tela: 


\begin{tabular}{|l|r|r|r|r|r|c|}
\hline \multirow{2}{*}{ OBRA } & \multicolumn{2}{|c|}{ OS SERTÕES } & \multicolumn{2}{c|}{ TERESA BATISTA } & \multicolumn{2}{c|}{ TOTAL GERAL } \\
\cline { 2 - 7 } & \multicolumn{1}{c|}{$\mathbf{N}$} & \multicolumn{1}{c|}{$\%$} & \multicolumn{1}{c|}{$\mathbf{N}$} & $\%$ & $\mathbf{N}$ & $\%$ \\
\hline Empréstimo simples & 191 & 30,3 & 97 & 29,2 & 288 & 29,9 \\
\hline Empréstimo + tradução literal & 2 & 0,3 & 0 & 0,0 & 2 & 0,2 \\
\hline Empréstimo + transposição & 12 & 2,1 & 1 & 0,3 & 14 & 1,5 \\
\hline Empréstimo + explicitação & 92 & 14,6 & 10 & 3,0 & 102 & 10,6 \\
\hline Empréstimo + adaptação & 1 & 0,2 & 0 & 0,0 & 1 & 0,1 \\
\hline Empréstimo + omissão & 2 & 0,3 & 0 & 0,0 & 2 & 0,2 \\
\hline Subtotal dos empréstimos & 300 & 47,8 & 108 & 32,5 & 408 & 42,5 \\
\hline Omissão & 12 & 1,9 & 6 & 1,8 & 18 & 1,9 \\
\hline Decalque e tradução literal & 15 & 2,4 & 11 & 3,3 & 26 & 3,0 \\
\hline Explicitação & 30 & 4,8 & 24 & 7,2 & 54 & 5,6 \\
\hline Modulação e adaptação & 244 & 38,7 & 155 & 46,7 & 399 & 41,5 \\
\hline Outros procedimentos & 29 & 4,4 & 28 & 8,5 & 57 & 5,5 \\
\hline TOTAL GERAL & $\mathbf{6 3 0}$ & $\mathbf{1 0 0 , 0}$ & $\mathbf{3 3 2}$ & $\mathbf{1 0 0 , 0}$ & $\mathbf{9 6 2}$ & $\mathbf{1 0 0 , 0}$ \\
\hline
\end{tabular}

Quadro I. Freqüência absoluta e relativa dos procedimentos tradutórios aplicados a marcas culturais, por obra ${ }^{4}$

O quadro acima é revelador a mais de um título. Como já foi indicado, na análise de traduções efetuada sobre seqüências textuais, o empréstimo comparece com um índice de freqüência bastante baixo (em média, próximo a 1,0 \%, podendo ser igual a $0 \%$ em determinados textos), e nem poderia ser de outro modo. Quando porém, destacamos os marcadores lingüísticos das especificidades culturais da Língua-Fonte (LF), a participação do empréstimo torna-se extremamente significativa, como também ocorre com a adaptação. A explicitação constitui o terceiro procedimento mais freqüente. Esta constatação é corroborada pelos resultados relatados em Corrêa (1998), que, para um corpus composto de três romances de Jorge Amado, apresenta, em média, as seguintes freqüências:

4 Este quadro constitui uma reorganização da Tabela 7 constante de Aubert (1998). 


\begin{tabular}{|l|c|c|c|c|}
\hline $\begin{array}{l}\text { OBRA } \\
\text { PROCEDIMENTO }\end{array}$ & $\begin{array}{c}\text { DONA FLOR } \\
\%\end{array}$ & $\begin{array}{c}\text { T. MILAGRES } \\
\%\end{array}$ & $\begin{array}{c}\text { T. BATISTA }^{6} \\
\%\end{array}$ & $\begin{array}{c}\text { MÉDIA } \\
\%\end{array}$ \\
\hline Empréstimos simples & 18,0 & 30,7 & 17,7 & 22,1 \\
\hline Empréstimos com grifo & 6,0 & 16,9 & 18,2 & 13,7 \\
\hline Empréstimos indiretos & 2,3 & 8,5 & 1,4 & 12,2 \\
\hline Total de empréstimos & 26,3 & 56,1 & 37,3 & 39,9 \\
\hline Omissão & 5,7 & 4,5 & 6,2 & 5,5 \\
\hline Decalque e tradução literal & 7,0 & 6,9 & 3,0 & 5,6 \\
\hline Explicitação & 18,5 & 7,2 & 14,2 & 13,3 \\
\hline Modulação e adaptação & 37,6 & 16,7 & 28,2 & 27,5 \\
\hline Outros procedimentos & 4,7 & 8,3 & 10,5 & 7,8 \\
\hline
\end{tabular}

Quadro II. Freqüência absoluta e relativa dos procedimentos tradutórios aplicados a marcas culturais, em Corrêa (1998): ${ }^{5}$

Em que pesem algumas discrepâncias com o estudo aqui relatado (vide nota 6 , infra), constata-se a persistência de tendências que validam as observações feitas no presente trabalho. Com efeito, no conjunto de textos analisados por Corrêa, os empréstimos, as adaptações e as explicitações predominam sobre os demais procedimentos. A tradução literal, embora também se faça presente, novamente fica significativamente abaixo dos demais, praticamente em posição equivalente à da omissão.

O estudo de Corrêa permite, ainda, fazer duas ilações acerca do empréstimo. Nesta análise, o empréstimo claramente predomina sobre os demais procedimentos. No caso específico de Tenda dos Milagres, a natureza do texto, em grande parte um "guia cultural" que convida o leitor a iniciar-se nos mistérios do universo soteropolitano, torna especialmente freqüente o uso, no texto original, de marcas lingüísticas da especificidade cultural, quer em termos de ocorrências de cada termo, quer pela varieda-

5 Dados extraídos de Corrêa (1998) e reorganizados de modo a possibilitar paralelo com o Quadro I. 6 As discrepâncias observadas na distribuição das modalidades em Teresa Batista entre os Quadros I e II devem-se a procedimentos operacionais e descritivos não totalmente coincidentes (vide, p. ex., os respectivos valores encontrados para a omissão). Embora tal não-coincidência seja, inevitavelmente, impeditiva de um tratamento quantitativo mais elaborado em base comparativa, a tendência geral resta confirmada, conforme comentado no corpo deste trabalho. 
de de termos. Neste aspecto, aproxima-se de Os Sertões, cujos dois primeiros capítulos têm precisamente por função familiarizar o leitor com o universo do sertão nordestino. Confrontando-se os dados dos Quadros I e II, percebe-se uma correlação qualitativa entre a natureza dos textos - descritivo-informativo acerca de culturas e regiões peculiares - e o peso significativamente maior do empréstimo em suas respectivas traduções. Mais precisamente, a tipologia textual, redundando em um número absoluto maior de marcas culturais, parece induzir a um número relativo maior de empréstimos. $^{7}$

Um segundo aspecto que se depreende de Corrêa diz respeito à margem de opção do tradutor. Considerando que Dona Flor e Seus Dois Maridos e Teresa Batista Cansada de Guerra têm entre si, do ponto de vista das marcas culturais textualizadas, uma organização e um peso bastante similares, poder-se-ia esperar um comportamento tradutório bastante similar. Não é o que ocorre. Em ambas as traduções, a ocorrência de empréstimos é elevada, mas em Teresa Batista os empréstimos superam as modulações e adaptações (o outro extremo da escala de procedimentos), enquanto que em Dona Flor estes procedimentos indiretos predominam sobre aqueles. Tal fato reforça a hipótese levantada desde o início, a de que o empréstimo, tanto quanto os demais procedimentos, exige uma intervenção ativa do tradutor, estando, portanto, sujeito, em grande medida, à liberdade individual de cada tradutor. A tendência estatística, de elevado número de empréstimos, é exatamente isso, uma tendência, não um automatismo do processo tradutório. A tipologia textual configura uma probabilidade comportamental, não uma essência da interação interlingual.

Finalmente, cabe observar que ambos os estudos indicam que a evasão ao obstáculo tradutório, teoricamente uma das quatro opções básicas abertas ao tradutor, constitui, efetivamente, um recurso utilizado, de forma bastante modesta (entre 5 e $6 \%$ das ocorrências). Ainda, a omissão pontual não representa, necessariamente, uma omissão textual. Com efeito, em Rebellion in the Backlands, por exemplo, o termo sertão (no singular ou no plural) foi omitido em um total de 3 ocorrências, ocorrendo, no entanto, sob outras formas (principalmente adaptações) em um total de 72 ocorrências ao longo dos dois primeiros capítulos da obra.

7 Esta afirmação é reforçada pelo fato de Dona Flor e Seus Dois Maridos e Tenda dos Milagres terem sido ambos vertidos para o inglês pela mesma tradutora, B. Shelby. Neste ponto, portanto, o idioleto de tradutor pesa menos do que a tipologia textual. Vide, no entanto, os comentários desenvolvidos no parágrafo seguinte. 
Pode surpreender, nos dois estudos em discussão, a ocorrência - é bem verdade que relativamente modesta - da tradução literal. Em tese, se o termo é exclusivo da cultura fonte, a tradução literal seria impossível. No caso presente, as traduções literais apresentam-se, na realidade, como variantes do decalque (no caso, decalque semântico, não de sentido), como o termo caldeirões traduzido como "cauldrons" (inclusive com as aspas substituindo o itálico constante do original).

Os dados sintetizados no Quadro I indicam, ainda, que o empréstimo pode co-ocorrer com outros procedimentos tradutórios. Veja-se, por exemplo:

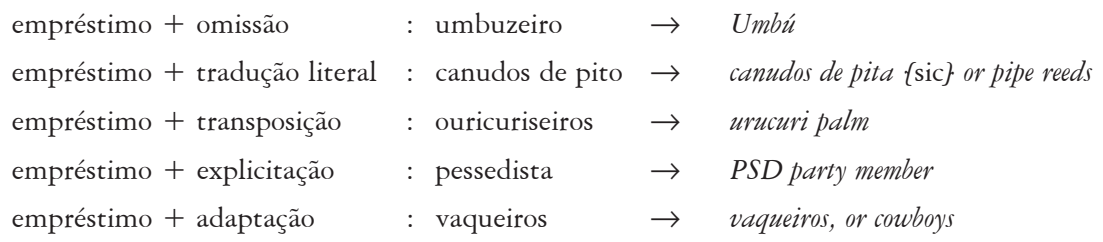

Embora raros (e encontrados quase que exclusivamente em um dos textos, sugerindo, portanto, tratar-se de marca idioletal de tradutor), essas combinações de procedimentos são reveladoras do esforço tradutório empreendido, do desenrolar de um processo decisório na busca da aproximação possível com a língua/cultura meta. De especial relevância é a combinação de empréstimo com explicitação, procedimento que assume quer a forma de aposto (sintaticamente explícito ou velado sob o manto de um sintagma nominal, ou pela aposição do próprio empréstimo), quer como nota de rodapé. ${ }^{8}$ Excepcionalmente, ocorre a relação inversa, com o empréstimo em rodapé apoiando um outro procedimento aplicado no corpo do texto. Veja-se, por exemplo:

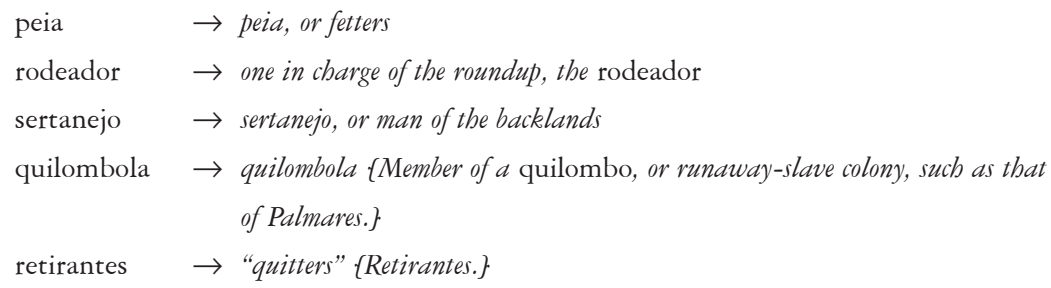

\footnotetext{
8 A nota de rodapé, freqüente em Os Sertões, inexiste em Teresa Batista, o que se explica pelas respectivas tipologias textuais.
} 
Observe-se, a propósito, que o empréstimo pode ser uma das várias soluções utilizadas para a tradução de um mesmo termo, ao longo do texto traduzido. Assim, por exemplo, o substantivo sertanejo vem traduzido, no decorrer dos dois primeiros capítulos de Os Sertões/Rebellion in the Backlands e em Teresa Batista como:

$\begin{array}{llc} & \text { tradução } & \text { ocorrências } \\ \text { SERTANEJO } & \text { backwoodsman } & 3 \\ \text { woodsman } & 1 \\ \text { sertanejo } & 16 \\ \text { sertanejo or man of the backlands } & 1 \\ \text { man } & 1 \\ \text { man of the binterland } & 1 \\ \text { man of the backlands } & 1 \\ \text { inhabitant of the backlands } & 2 \\ \text { back lander } & 1 \\ \text { native } & 1\end{array}$

o que é indicativo claro ser o empréstimo não uma estratégia isolada, e sim parte integrante de um conjunto de recursos mobilizados pelo tradutor para a superação da barreira posta pelas realidades extra-lingüísticas discrepantes, sem incorrer no risco oposto, de "apagar" a alteridade cultural preexistente. ${ }^{9}$

A situação é, porém, ainda mais complexa. Para além das combinatórias de procedimentos, ocorrem também alterações de outras ordens. Não raro, acrescenta-se ao empréstimo uma marca gráfica (aspas ou itálico ou, mesmo, ambos), como já vimos acima. Ocasionalmente, ocorre o contrário, e um termo original destacado perde a marca gráfica distintiva, como em campos gerais, reproduzido na tradução de Os Sertões como campos gerais. Por vezes, podem ocorrer alterações gráficas (reduplicação de consoantes, a introdução do dígrafo "ss" em substituição ao "ç" ou outras alterações aparentemente aleatórias - introdução ou eliminação de acentos), como em

9 O emprego do empréstimo paralelamente a outros recursos (em especial, a explicitação, a adaptação e, ocasionalmente, a tradução literal) ao longo do texto requer uma abordagem longitudinal que foge ao escopo do presente trabalho. Para um primeiro estudo com tal abordagem, vide Corrêa (1998). 
cajuís traduzido como cajuys, juás convertido em joaz, "sabará-buçu” reproduzido como "sabará-bussú", etc. ${ }^{10}$

\begin{tabular}{|c|c|c|c|c|c|}
\hline \multicolumn{2}{|c|}{$\begin{array}{l}\text { SUBTIPOS DE } \\
\text { EMPRÉSTIMOS SIMPLES }\end{array}$} & \multirow{2}{*}{$\frac{\text { Os Sertões }}{101}$} & \multirow{2}{*}{$\frac{\text { Teresa Batista }}{33}$} & \multirow{2}{*}{$\begin{array}{r}\text { Total } \\
134\end{array}$} & \multirow{2}{*}{$\begin{array}{c}\% \\
46,6\end{array}$} \\
\hline 1 & sem alterações & & & & \\
\hline 2 & itálico & 4 & 55 & 59 & 20,5 \\
\hline 3 & alteração de grafia & 44 & 4 & 48 & 16,8 \\
\hline 4 & eliminação do itálico & 4 & 0 & 4 & 1,4 \\
\hline 5 & itálico e alteração de grafia & 3 & 0 & 3 & 1,0 \\
\hline 6 & itálico e eliminação de aspas & 1 & 0 & 1 & 0,3 \\
\hline 7 & $\begin{array}{l}\text { eliminação do itálico e adição } \\
\text { de aspas }\end{array}$ & 1 & 0 & 1 & 0,3 \\
\hline 8 & $\begin{array}{l}\text { eliminação do itálico e alteração } \\
\text { de grafia }\end{array}$ & 1 & 0 & 1 & 0,3 \\
\hline & subtotal de alterações gráficas & 58 & 59 & 117 & 40,6 \\
\hline 9 & empréstimo de outro termo da LF & 1 & 5 & 6 & 2,1 \\
\hline 10 & $\begin{array}{l}\text { empréstimo de outro termo } \\
\text { da LF e eliminação de itálico }\end{array}$ & 4 & 0 & 4 & 1,4 \\
\hline 11 & empréstimo de outra língua & 26 & 0 & 26 & 9,0 \\
\hline 12 & $\begin{array}{l}\text { empréstimo de outra língua e } \\
\text { eliminação de itálico }\end{array}$ & 1 & 0 & 1 & 0,3 \\
\hline & subtotal de empréstimos indiretos & 32 & 5 & 37 & 12,8 \\
\hline & TOTAL & 191 & 97 & 288 & 100,0 \\
\hline
\end{tabular}

Quadro III. Subtipos de empréstimos simples

10 Considerando a data de publicação de Rebellion in the Backlands (1944), é muito provável que o tradutor S. Putnam tenha utilizado como texto fonte uma edição ainda em ortografia tradicional. Nesta hipótese, as alterações gráficas observadas seriam enganosas, o desvio, se houver, estando antes nas edições brasileiras pós-reformas ortográficas. A hipótese é reforçada pelo índice sensivelmente menor de alterações gráficas observadas em Teresa Batista Home from the Wars. Resta, de todo modo, a constatação de que a alteração na grafia constitui um dos subtipos de empréstimo. 
Uma outra variante dos empréstimos é de natureza mais propriamente lexical. Em circunstâncias ainda a serem melhor esclarecidas, o tradutor opta por efetuar uma espécie de empréstimo indireto; ou seja, não se vale do termo constante do original, mas insere um outro termo da LF ou, ainda, um termo de uma terceira língua (no caso da relação tradutória português $\rightarrow$ inglês, essa terceira língua é, mais freqüentemente, a castelhana). Assim, por exemplo, em Teresa Batista o termo gafieira aparece traduzido como samba e, em Rebellion in the Backlands, araquã é vertido como jacu e mestiço como mestizo. O Quadro III apresenta os dados quantitativos registrados para estes dois casos, em confronto com o total de empréstimos simples (ou seja, não combinados com outros procedimentos).

As alterações de grafismo e de ortografia, bem como os empréstimos indiretos, ocorrem em ambas as traduções, denotando, portanto, constituírem sub-procedimentos gerais (vide, porém, nota 10). A multiplicidade e a flutuação das soluções dadas para o grafismo, evidente em Rebellion in the Backlands, pode estar indicando uma dificuldade de estabelecer uma norma de conduta para os empréstimos, norma essa que já aparece estabilizada em Teresa Batista, com o uso exclusivo do itálico como marcador gráfico de empréstimo. Seja como for, na média são $40 \%$ das ocorrências de empréstimos simples (em Teresa Batista, acima de 60\%) vêm graficamente assinalados como tais.

Os empréstimos indiretos são raros em Teresa Batista, ao contrário do que ocorre em Rebellion in the Backlands, em que representam quase 17\% das ocorrências de empréstimos simples. O corpus é insuficiente para determinar se tal fato se deve meramente aos idioletos dos respectivos tradutores, ou se há fatores vinculados à diacronia da relação entre a cultura americana e a cultura brasileira que possam justificar a redução em praticamente $2 / 3$ das ocorrências desta modalidade de empréstimo. Resta, de todo modo, o procedimento em si, de interesse qualitativo evidente. Principalmente em Teresa Batista, o que parece ocorrer é um recurso a termos da LF supostamente de conhecimento mais geral na cultura de recepção, e/ou um processo de atualização. Observe-se os cinco casos registrados:

$$
\begin{array}{ll}
\text { conto } & \rightarrow \text { cruzeiro } \\
\text { mil-réis } & \rightarrow \text { cruzeiros } \\
\text { mameluco } & \rightarrow \text { mulatto } \\
\text { gafieira } & \rightarrow \text { samba } \\
\text { rebolado } & \rightarrow \text { samba }
\end{array}
$$


em que mesmo o termo mulatto por mameluco - estritamente falando, um erro - parece atender ao propósito de manutenção de "cor local" pelo empréstimo, recorrendo a um sentido mais genérico (indivíduo de etnia mista), ainda que sacrificando o sentido estrito (indivíduo com ascendência mista branco + índio em oposição a branco + negro).

\section{Considerações finais}

Os dados e as reflexões tecidas no que precede constituem indicativos claros de que o empréstimo, enquanto procedimento de tradução, revestese de elevado grau de complexidade e apresenta facetas bastante diversas. Nas múltiplas variantes registradas, formais, indiretas (intra e interlinguais) e em combinação com outros procedimentos, o corpus analisado apresentou um total de 37 realizações distintas. Ainda que bom número destas venham a ser tidas como representativas de uma etapa experimental na lide com a tradução de termos culturalmente marcados (hipótese levantada para a grande flutuação observada em Rebellion in the Backlands), e, portanto, em tese, não produtivas na atualidade, restam pelo menos uma dezena de subprocedimentos tradutórios envolvendo o empréstimo como elemento central ou acessório.

O presente estudo e, em grau mais abrangente, o trabalho de Corrêa (1998), indicam, ainda, que o empréstimo - tanto, é de intuir, quanto qualquer outro procedimento do ato tradutório - não pode ser avaliado apenas pontualmente, no entorno co-textual imediato de sua ocorrência. Para além de sua dimensão frástica, há uma dimensão textual na qual o empréstimo se insere e no âmbito do qual, em grande parte, se justifica e se torna eficaz como solução tradutória. O relato de pesquisa ora apresentado tem, portanto, um caráter sobretudo exploratório: aos dados quantitativos e distribucionais caberá acrescer, além de novos dados, envolvendo outras tipologias textuais, outros pares de idiomas e outras direções tradutórias, investigações de ordem qualitativa, nas dimensões semântica, pragmática e textual e, muito possivelmente, investigações de ordem diacrônica.

De todo modo, evidencia-se, desde já, o fato do empréstimo, ao contrário do sugerido por Vinay e Darbelnet (1958) e do que afirma Wills (1982) e confirmando a suspeita de Barbosa (1990), não constituir um 
procedimento "fácil" do traduzir. Tanto quanto o indicado por Fregonezi (1984) para a transposição, o empréstimo se desdobra em diversas opções formais, estilísticas e pragmáticas, ora se impondo como solução única (obrigatória), necessitando de outros elementos de apoio inseridos na urdidura do texto traduzido, ora transparecendo como opção deliberada, buscada pelo tradutor para gerar determinados efeitos na tradução. Parece poder servir, paralela e simultaneamente, tanto à perspectiva assimilativa (Comunicativa, domesticadora) quanto à abordagem matricial (semântica, estrangeirizadora). Nesta constatação de sua complexidade, convida desde já a novas investigações.

E-mail: fhaubert@usp.br Recebido em fevereiro de 2002

\section{REFERÊNCIAS}

Alves, I. 1983. Modalidades de tradução: uma avaliação do modelo proposto por Vinay E Darbelnet. Dissertação de mestrado. São Paulo: PUCSP.

Amado, J. 1972. Teresa Batista cansada de guerra. São Paulo: Martins. Tradução norte-americana de SHeLBY, B. 1975. Teresa Batista home from the wars. Nova York: Alfred A. Knopf.

Aubert, F. H. 1998. Modalidades de tradução: teoria e resultados. TradTerm 5(1). São Paulo: CITRAT/FFLCH-USP: 99-128.

Aubert, F.H. 2001. Preconceitos lingüísticos subjacentes ao Projeto de Lei n. ${ }^{\circ}$ 1676/99. In: Urbano, H. et al. Dino Preti e seus temas: oralidade, literatura, mídia e ensino. São Paulo: Cortez.

Barbosa, H. G. 1990. Procedimentos técnicos da tradução: uma nova proposta. Campinas: Pontes.

CORRÊA, R. H. M. A. 1998. Barreiras culturais da tradução: Um estudo de obras de Jorge Amado traduzidas para o inglês. Tese de doutorado. São Paulo: FFLCH-USP.

Cunha, E. 1902. Os sertões. 24a ed. 1956. Rio de Janeiro: Francisco Alves. Tradução norte-americana de PutNAm, S. 1944. Rebellion in the backlands. Chicago: UCP.

Darin, L. 1986. Translation modalities in the comparison of English and Portuguese - Analysis of excerpts taken from C. Castañeda's novel "The Teachings of D. Juan" or "A Erva do Diabo". Dissertação de mestrado. Univ. of Exeter.

Fregonezi, D. E. 1984. A tradução: uma abordagem lingüística. Tese de doutorado. Araraquara, UNESP. 
Newmark, P. 1981. Approaches to translation. Oxford: Pergamon.

NidA, E. 1945. Linguistics and ethnology in translation problems. Word 1.2.:194-208.

Schleirmacher, F. 1813. Über die verschiedenen Methoden des Übersetzens. In StÖRIG, H. J. 1973. Das Problem des Übersetzens. Stuttgart.

Venuti, L. 1995. The translator's invisibility - a history of translation. Londres/Nova York: Routledge.

Vinay, J. P. \& Darbelnet, J. 1958. Stylistique comparée du français et de l'anglais. Paris: Didier.

WILls, W. 1982. The science of translation: problems and methods. Tübingen: Gunter Narr.

Zanotto, P. 1993. Tipos de texto e modalidades de tradução. Tese de doutorado. São Paulo: USP. 